\title{
Prognostic impact of history of follicular Iymphoma, induction regimen and stem cell transplant in patients with MYC/BCL2 double hit lymphoma
}

\author{
Shaoying Li ${ }^{1}$, Annapurna Saksena ${ }^{1}$, Parth Desai ${ }^{1}$, Jie $\mathrm{Xu}^{1}{ }^{1}$, Zhuang Zuo ${ }^{1}$, Pei Lin ${ }^{1}$, \\ Guilin Tang ${ }^{1}$, C. Cameron Yin ${ }^{1}$, Adam Seegmiller ${ }^{2}$, Jeffrey L. Jorgensen ${ }^{1}$, Roberto $\mathbf{N}$. \\ Miranda ${ }^{1}$, Nishitha M Reddy ${ }^{3}$, Carlos Bueso-Ramos ${ }^{1}$, L. Jeffrey Medeiros ${ }^{1}$ \\ ${ }^{1}$ Department of Hematopathology, The University of Texas MD Anderson Cancer Center, Houston, TX, USA \\ ${ }^{2}$ Division of Hematopathology, Vanderbilt University Medical Center, Nashville, TN, USA \\ ${ }^{3}$ Division of Hematology/Oncology, Vanderbilt University Medical Center, Nashville, TN, USA \\ Correspondence to: Shaoying Li, email: sli6@mdanderson.org
}

Keywords: double hit lymphoma, MYC/8q24, BCL2/t(14;18)(q32;q21), high grade B cell lymphoma

Received: February 08, 2016

Accepted: April 26, 2016

Published: May 19, 2016

\section{ABSTRACT}

MYC/BCL2 double hit lymphoma (DHL) has been the subject of many studies; however, no study has systemically compared the clinicopathologic features and prognostic factors between patients with de novo disease versus those with a history of follicular lymphoma (FL). In addition, the prognostic importance of several other issues remains controversial in these patients. In this retrospective study, we assess 157 patients with MYC/BCL2 DHL including 108 patients with de novo disease and 49 patients with a history of FL or rarely other types of low-grade B-cell lymphoma. Patients received induction chemotherapy regimens including $61 \mathrm{R}-\mathrm{CHOP}, 31 \mathrm{R}-\mathrm{EPOCH}$, 29 R-Hyper-CVAD, and 23 other regimens. Thirty-nine patients received a stem cell transplant (SCT) including 31 autologous and 8 allogeneic. Sixty-two patients achieved complete remission (CR) after induction chemotherapy. Median overall survival (OS) was 19 months. Clinicopathologic features were similar between patients with de novo tumors versus those with a history of FL $(P>0.05)$. Using multivariate analysis, achieving CR, undergoing SCT, stage and the International Prognostic Index were independent prognostic factors for OS. Stem cell transplantion was associated with improved OS in patients who failed to achieve $C R$, but not in patients who achieved $C R$ after induction chemotherapy. In conclusion, patients with MYC/BCL2 DHL who present with de novo disease and patients with a history of FL have a similarly poor prognosis. Achievement of $C R$, regardless of the induction chemotherapy regimen used, is the most important independent prognostic factor. Patients who do not achieve CR after induction chemotherapy may benefit from SCT.

\section{INTRODUCTION}

Double hit lymphoma (DHL) is a large B cell lymphoma with concurrent translocations involving $M Y C$ and another oncogene [1]. Double hit lymphoma represents up to $14 \%$ of the patients with aggressive B-cell lymphoma and MYC/BCL2 DHL is most common, representing approximately $65 \%$ of all cases, followed by $M Y C / B C L 2 / B C L 6$ triple hit lymphoma, $20 \%$, and $M Y C /$ $B C L 6$ DHL, $\sim 15 \%$.[2-5] MYC rearrangement is found in multiple B cell lymphomas including Burkitt lymphoma, diffuse large B cell lymphoma (DLBCL), high-grade B-cell lymphoma not otherwise specified (NOS) (previously known as B cell lymphoma, unclassifiable with features intermediate between DLBCL and Burkitt lymphoma [BCLU]), and rarely other neoplasms $[6,7]$. $M Y C$ is a highly regulated transcription factor that is involved in cell cycle regulation, cell metabolism, mitochondrial biogenesis, nucleic acid synthesis, and apoptosis [8]. When $M Y C$ is up-regulated due to translocation or other mechanisms, the growth-promoting effects of $M Y C$ can lead to exuberant cell proliferation, 
especially in the presence of BCL2 translocation which results in overexpression of the anti-apoptotic protein BCL2, as seen in MYC/BCL2 DHL.

$M Y C / B C L 2$ DHL has been studied extensively in literature [3, 4, 9-23]. Patients with $M Y C / B C L 2$ DHL usually present with advanced stage disease, extranodal involvement, and high serum lactate dehydrogenase (LDH) levels. Bone marrow (BM) and central nervous system (CNS) involvement are common and the International Prognostic Index (IPI) score is often highintermediate or high. The morphology of these cases usually resembles that of DLBCL or BCLU. Most cases have a germinal center B-cell immunophenotype and a high proliferation (Ki67) rate. Despite of a variety of treatment approaches, patients with $M Y C / B C L 2$ DHL have a poor prognosis with a median overall survival of less than 2 years [3, 4, 11, 13-15, 17, 19, 23].

Multiple studies on the prognosis of patients with $M Y C / B C L 2$ DHL have reported a number of prognostic factors. Johnson et al., in a study of 54 patients, identified high IPI score, BM involvement, BCLU morphology, IG partner, and BCL2 expression as predictors of poorer prognosis [11]. In contrast, in a study from MD Anderson Cancer Center $(n=129$, $93 M Y C / B C L 2$ DHL), performance status, bone marrow involvement and treatment regimen were independent prognostic factors in multivariate analysis [18]. A multicenter retrospective study of 311 cases of DHL with 270 MYC/BCL2 DHL showed that WBC count, serum LDH, stage, and CNS involvement are independent prognostic factors in multivariate analysis. Intensive induction was associated with improved progression free survival, but not OS [20]. The results of these studies illustrate the current lack of consensus regarding prognostic factors in patients with $M Y C / B C L 2$ DHL.

Although multiple studies on $M Y C / B C L 2$ DHL have been published, to date no study has systemically compared the clinicopathologic features and prognostic factors between patients with de novo MYC/BCL2 DHL versus those patients with a history of follicular lymphoma (FL). In addition, the prognostic importance of several other issues in this patient group remains controversial. These questions include the following: 1) Is a history of follicular lymphoma predict a worse prognosis in patients with $M Y C / B C L 2$ DHL? 2) What is the prognostic impact of DLBCL versus high-grade B-cell lymphoma NOS (BCLU) morphology? 3) What is the prognostic impact of the $M Y C$ translocation partner? 4) Does MYC or BCL2 expression have additional prognostic value; and 5) What appears to be the most effective therapy? To address these issues, we systematically studied the clinicopathologic features of 157 patients with $M Y C / B C L 2$ DHL including 108 with de novo disease and 49 patients with a history of low-grade B-cell lymphoma, mostly FL.

\section{RESULTS}

\section{De novo MYC/BCL2 DHL}

\section{Baseline clinicopathologic features}

There were 108 patients with untreated de novo $M Y C / B C L 2$ DHL, including 73 men and 35 women with a median age of 61 years (range, 18-87). The baseline clinicopathologic features are summarized in Table 1. Half of the patients presented with bone marrow and/or other extranodal sites of involvement by disease. The CNS was involved in 11 of $52(21 \%)$ patients who underwent morphologic evaluation. Most patients presented with an elevated serum LDH, high Ann Arbor stage (III/IV) disease, and high-intermediate to high IPI score. Sixty-four (59\%) tumors were classified as DLBCL and 44 (41\%) were classified as high-grade large B-cell lymphoma, NOS (previously known as BCLU). Most tumors showed expression of CD10, BCL2, and BCL6 with a high Ki67 proliferation rate. MYC and BCL2 were dually expressed in $72 \%$ of tumors assessed (Figure 1; Table 1/column 1). Virtually all tumors had a GCB immunophenotype using the Hans algorithm.[24] In 28 of 30 cases with karyotypic data, the $M Y C$ translocation partner gene was: 7 immunoglobulin heavy chain $(I G H), 16 I G$ light chain ( $I G K$ and $I G L)$, and 5 (18\%) non- $I G$ genes.

\section{Treatment and response}

Patients with de novo MYC/BCL2 DHL were treated with different regimens with or without stem cell transplant (SCT). Ninety-nine patients had complete induction regimen and SCT information available. For this group, 40 patients received rituximab, cyclophosphamide, doxorubicin, vincristine, and prednisone (R-CHOP), 22 etoposide, prednisone, vincristine, cyclophosphamide, doxorubicin, and rituximab (R-EPOCH), 28 rituximab, hyperfractionated cyclophosphamide, vincristine, doxorubicin, dexamethasone, cytarabine and methotrexate (R-Hyper-CVAD), and 9 other chemotherapy regimens (including only CHOP in earlier years). After initial induction chemotherapy, 48 patients achieved complete remission (CR), 14 partial remission (PR), and 31 had persistent or progressive disease (primary refractory disease, PRD). Six patients did not complete induction or evaluation. Twenty-two patients also received SCT including 18 autologous and 4 allogeneic; 14 patients were in CR at the time of SCT. The median overall survival was 18.6 months (Table 1).

\section{Prognostic factors}

All 17 collected variables were evaluated by univariate analysis for impact on OS. More than one extranodal site of involvement and high stage (III/IV) were associated with worse OS. Complete response to frontline chemotherapy and SCT were associated with better OS ( $p<0.05$, Figure 2). Bone marrow and CNS 
Table 1: Clinicopathologic features of de novo, transformed, and all DHL patients

\begin{tabular}{|c|c|c|c|c|}
\hline Features & $\begin{array}{c}\text { De Novo DHL } \\
(n=108) \% \\
\text { (Positive/Evaluated) }\end{array}$ & $\begin{array}{c}\text { Transformed DHL } \\
(n=49) \% \\
\text { (Positive/Evaluated) }\end{array}$ & $\begin{array}{l}\text { All DHL }(n=157) \% \\
\text { (Positive/Evaluated) }\end{array}$ & $\begin{array}{l}\mathrm{P} \text { (De novo vs } \\
\text { Transformed) }\end{array}$ \\
\hline Medain Age (yrs, range) & $61(18-87)$ & $59(32-86)$ & $61(18-87)$ & \\
\hline Age $\geq 60($ yrs $)$ & $62(67 / 108)$ & $45(22 / 49)$ & $57(89 / 157)$ & 0.056 \\
\hline Male:Female & $73: 35$ & $30: 19$ & $103: 54$ & \\
\hline Previous FL/B-NHL & & $100(49 / 49)$ & $31(49 / 157)$ & \\
\hline BM positive & $49(45 / 91)$ & $51(23 / 45)$ & $50(68 / 136)$ & 1.000 \\
\hline CNS positive & $21(11 / 52)$ & $12(3 / 26)$ & $18(14 / 78)$ & 0.526 \\
\hline Extranodal sites $\geq 2$ & $54(58 / 108)$ & $55(27 / 49)$ & $54(85 / 157)$ & 1.000 \\
\hline Elevated serum LDH & $83(71 / 86)$ & $86(36 / 42)$ & $84(107 / 128)$ & 0.952 \\
\hline Stage III or IV & $88(84 / 96)$ & $85(41 / 48)$ & $87(125 / 144)$ & 1.000 \\
\hline High-Intermediate/High IPI & $82(75 / 91)$ & $82(36 / 44)$ & $82(111 / 135)$ & 1.000 \\
\hline \multicolumn{5}{|l|}{ Morphology } \\
\hline DLBCL & $59(64 / 108)$ & $57(28 / 49)$ & $58.5(92 / 157)$ & 1.000 \\
\hline BCLU & $41(44 / 108)$ & $35(17 / 49)$ & $39(61 / 157)$ & 0.487 \\
\hline DLBCL+FL & 0 & $8(4 / 49)$ & $2.5(4 / 157)$ & \\
\hline \multicolumn{5}{|l|}{ Immunophenotype } \\
\hline CD10 & $97(99 / 102)$ & $100(49 / 49)$ & $98(148 / 151)$ & 0.551 \\
\hline BCL6 & $93(64 / 69)$ & $87(26 / 30)$ & $92(90 / 98)$ & 0.448 \\
\hline BCL2 & $92(87 / 95)$ & $91(42 / 46)$ & $91(129 / 141)$ & 1.000 \\
\hline MYC & $80(32 / 40)$ & $80(16 / 20)$ & $80(48 / 60)$ & 1.000 \\
\hline MYC/BCL2 Coexpress & $72(28 / 39)$ & $70(14 / 20)$ & $71(42 / 59)$ & 0.810 \\
\hline Ki67 $\geq 70 \%$ (Ki67 range) & $84(20-100)$ & $84(20-90)$ & $84(20-100)$ & \\
\hline GCB subtype & $99(102 / 103)$ & $100(49 / 49)$ & $99(151 / 152)$ & 1.000 \\
\hline \multicolumn{5}{|l|}{ Cytogenetics } \\
\hline Complex karyotype & $100(30 / 30)$ & $100(16 / 16)$ & $100(46 / 46)$ & 1.000 \\
\hline IGH as MYC partner & $25(7 / 28)$ & $50(6 / 12)$ & $33(13 / 40)$ & 0.130 \\
\hline Light chain as Partner & $57(16 / 28)$ & $25(3 / 12)$ & $48(19 / 40)$ & 0.150 \\
\hline Non-IG MYC partner & $18(5 / 28)$ & $25(3 / 12)$ & $20(8 / 40)$ & 0.677 \\
\hline \multicolumn{5}{|l|}{ Initial Chemotherapy } \\
\hline R-CHOP & $40(40 / 99)$ & $31(14 / 45)$ & $38(54 / 144)$ & 0.354 \\
\hline R-EPOCH & $22(22 / 99)$ & $27(12 / 45)$ & $24(34 / 144)$ & 0.282 \\
\hline R-HyperCVAD & $23(28 / 99)$ & $13(6 / 45)$ & $24(34 / 144)$ & 0.282 \\
\hline Other & $9(9 / 99)$ & $29(13 / 45)$ & $15(22 / 144)$ & 0.005 \\
\hline With SCT & $22(22 / 99)$ & $38(17 / 45)$ & $27(39 / 144)$ & 0.068 \\
\hline $\mathbf{C R}$ & $48(48 / 99)$ & $33(15 / 45)$ & $44(63 / 144)$ & 0.107 \\
\hline Median OS (Months) & 18.6 & 19 & 19 & 0.740 \\
\hline
\end{tabular}

involvement $(p=0.089)$ and IPI score tended to be associated with a worse prognosis but had a borderline $p$ value (Figure 2, column 1). All other factors assessed, including morphologic classification, BCL2, MYC, or MYC/BCL2 dual expression, MYC partner gene, and chemotherapy regimen did not predict prognosis (Supplementary Figure 1, column 1).

\section{$M Y C / B C L 2$ DHL in patients with history of follicular lymphoma}

There were 49 patients with $M Y C / B C L 2$ DHL who had a history of FL $(n=46)$ or other type of low-grade non-Hodgkin $\mathrm{B}$ cell lymphoma $(n=3)$. There were 30 men and 19 women with a median age of 59 years (range, 
32-86). Patients older than 60 years were less common in this group compared to patients with de novo disease $(p=0.056)$. The clinicopathologic features of these patients were similar to those with de novo MYC/BCL2 DHL (Table 1).

Forty-five patients had complete induction regimen and SCT information available; 14 patients received R-CHOP, 12 R-EPOCH, and 6 R-Hyper-CVAD. Due to the previous treatment for low-grade lymphoma, 13 patients received treatment other than the above mentioned regimens, which were used significantly more often than in patients with de novo tumors as expected (29\% vs $9 \%$, $p=0.005)$. After induction chemotherapy, 14 patients reached $\mathrm{CR}, 7 \mathrm{PR}$, and 22 had $\mathrm{PRD}$. The $\mathrm{CR}$ rate was lower for patients in this group compared with patients with de novo disease, however, this difference did not reach statistical significance (33\% vs 48\%, $p=0.107$; Table 1). Seventeen patients received SCT, 13 autologous and 4 allogeneic, including 10 patients who achieved CR prior to SCT. Relatively more patients received SCT compared to those with de novo disease ( $p=0.068$, Table 1$)$.

In a univariate analysis, bone marrow involvement, more than one extranodal site of disease, high Ann Arbor stage (III/IV) and high-intermediate/high IPI were associated with a worse OS $(p<0.05)$, In contrast, achievement of CR and SCT were associated with a better OS ( $p<0.05$, Figure 2, column 2). All other factors assessed including morphologic classification, BCL2, MYC, or MYC/BCL2 dual expression, $M Y C$ partner gene, and chemotherapy regimen did not predict prognosis (Supplementary Figure 1, column 2). Only 3 patients in this group had CNS involvement and therefore survival analysis was not performed. The median OS of 19 months was similar to that of patients with de novo disease, either for all patients (Figure 3A, $p=0.74$ ) or only those who did not undergo SCT (Figure not show, $p=0.252$ ).

\section{All $M Y C / B C L 2$ DHL cases}

Since the clinicopathologic features and prognosis were similar for patients with de novo and for patients with a history of low-grade B-cell lymphoma (46/49 FL), we combined these cases into one group for further assessment of prognostic factors (Table 1, column 3). After a median follow up of 19 months (range, 2 months to 11.7 years), the median OS for all 157 patients was 19 months. The 2 -year survival rate was $47 \%$. In univariate analysis, involvement of bone marrow, CNS disease $(p=0.033)$, more than one extranodal site of lymphoma; stage; IPI score; achievement of CR; and undergoing a SCT were prognostic factors for OS (Figure 2, column 3 and Table 2). All other factors assessed including history
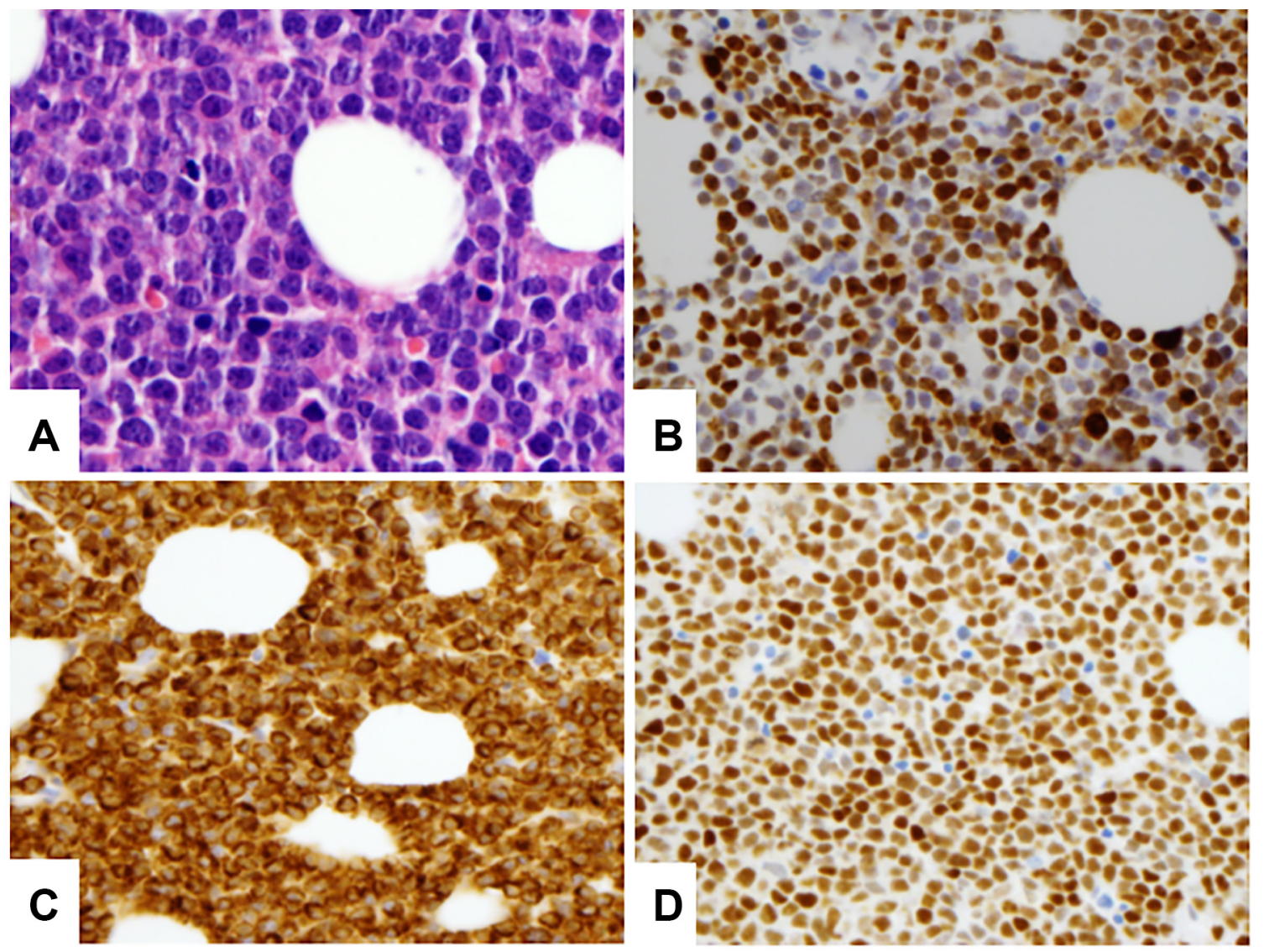

Figure 1: A representative case of DHL with DLBCL morphology (A), high Ki67 proliferation rate (B), BCL2 (C) AND MYC (D) dual expression (A) 600×, B-D. 400×). 
Table 2: Univariate analysis of clinicopathologic features predictive of overall survival in all DHL patients

\begin{tabular}{|l|c|c|c|}
\hline \multicolumn{2}{c}{ Features } & Hazard Ratio & 95\% Confidence Interval \\
\hline Age (> 60 vs $\leq \mathbf{6 0}$ yrs) & 1.20 & $0.76-1.90$ & 0.440 \\
\hline Male vs Female & 0.78 & $0.47-1.27$ & 0.300 \\
\hline History of FL/B-NHL & 1.22 & $0.73-2.05$ & 0.440 \\
\hline BM involvement & $\mathbf{1 . 8 6}$ & $\mathbf{1 . 1 7 - 3 . 0 2}$ & $\mathbf{0 . 0 0 9}$ \\
\hline CNS involvement & $\mathbf{1 . 9 3}$ & $\mathbf{1 . 0 1 - 5 . 0 3}$ & $\mathbf{0 . 0 4 9}$ \\
\hline Extranodal sites $\geq \mathbf{2}$ & $\mathbf{2 . 1 0}$ & $\mathbf{1 . 3 1 - 3 . 2 8}$ & $\mathbf{0 . 0 0 2}$ \\
\hline Elevated serum LDH & 1.64 & $0.85-2.81$ & 0.160 \\
\hline Stage III or IV & $\mathbf{4 . 7 9}$ & $\mathbf{1 . 5 5 - 4 . 7 4}$ & $\mathbf{0 . 0 0 1}$ \\
\hline IPI (H/H-I vs L/L-I) & $\mathbf{2 . 4 9}$ & $\mathbf{1 . 1 9 - 3 . 5 7}$ & $\mathbf{0 . 0 1 1}$ \\
\hline BCLU vs DLBCL & 0.88 & $0.55-1.41$ & 0.601 \\
\hline BCL2 protein (+ vs -) & 1.65 & $0.72-3.22$ & 0.270 \\
\hline MYC protein (+ vs -) & 1.10 & $0.33-3.64$ & 0.874 \\
\hline MYC \& BCL2 (DE vs Non-DE) & 1.55 & $0.56-4.06$ & 0.420 \\
\hline MYC partner (IG vs Non-IG) & 1.54 & $0.52-4.12$ & 0.474 \\
\hline Initial Chemotherapy & & & 0.545 \\
\hline R-CHOP vs R-EPOCH & 1.27 & $0.61-2.60$ & 0.751 \\
\hline R-CHOP vs R-HCVAD & 1.01 & $0.61-2.00$ & $\mathbf{0 . 0 0 3}$ \\
\hline Stem cell transplant & $\mathbf{0 . 4 2}$ & $\mathbf{0 . 2 9 - 0 . 7 8}$ & $<\mathbf{0 . 0 0 0 1}$ \\
\hline CR after initial chemotherapy & $\mathbf{0 . 3 4}$ & $\mathbf{0 . 5 0}$ & \\
\hline
\end{tabular}

Bold: prognostic factors with $P<0.05$; DE: dual expressor.

of FL, morphologic classification, BCL2, MYC, or MYC/BCL2 dual expression, MYC partner gene, and type of induction therapy did not predict prognosis (Supplementary Figure 1, Table 2). In patients with bone marrow involvement, we also compared bone marrow involvement by MYC/BCL2 DHL (concordant) versus low-grade B-cell lymphoma (discordant) and there was no significant difference in OS $(p=0.24)$.

The prognostic effect of SCT was further evaluated in patients with $\mathrm{CR}, \mathrm{PR}$, or PRD. As shown in Figures 3B-3D, SCT was significantly associated with improved OS in patients with PRD or PR ( $p=0.003$ and 0.09 respectively), but not in patients who achieved CR $(p=0.963)$ after induction chemotherapy. There was no significant statistical difference in OS between patients who received an allogeneic transplant $(n=8)$ compared to those who received an autologous transplant $(n=31)$ $(p=0.18)$, although the patients numbers are small, particularly in the allogeneic SCT group.

All the factors predictive of OS by univariate analysis were entered for multivariate Cox regression analysis (Table 3). After model selection, high stage (III/IV vs I/II) and high IPI (H/H-I vs L/L-I) were negative independent prognostic factors for OS $(P<0.05)$. Achievement of CR and receiving SCT after induction were positive independent prognostic factors for OS $(p<0.001)$. Type of induction chemotherapy, also included in multivariate analysis to exclude the effect of different treatments, was not a prognostic factor for OS ( $p=0.723$ for R-EPOCH vs R-CHOP, and 0.894 for R-Hyper-HCVAD vs R-CHOP).

\section{DISCUSSION}

MYC/BCL2 DHL has been well studied in the literature and yet no studies have systemically compared the clinicopathologic features of patients who present with de novo disease versus patients with a history of low-grade B-cell lymphoma, mostly FL, and then develop $M Y C /$ $B C L 2$ DHL. Other issues related to prognosis also remain controversial in this patient group which, in part, may be related to the small numbers of patients in many studies as well as the inclusion of different types of DHL.

Others have reported that patients with DLBCL transformed from FL or other type of low-grade B cell lymphoma have a worse prognosis than patients with de novo DLBCL, although the difference may be diminished in the era of rituximab therapy $[25,26]$. It seems likely that MYC/BCL2 DHL arising in a patient with a history of FL is a manifestation of histologic 

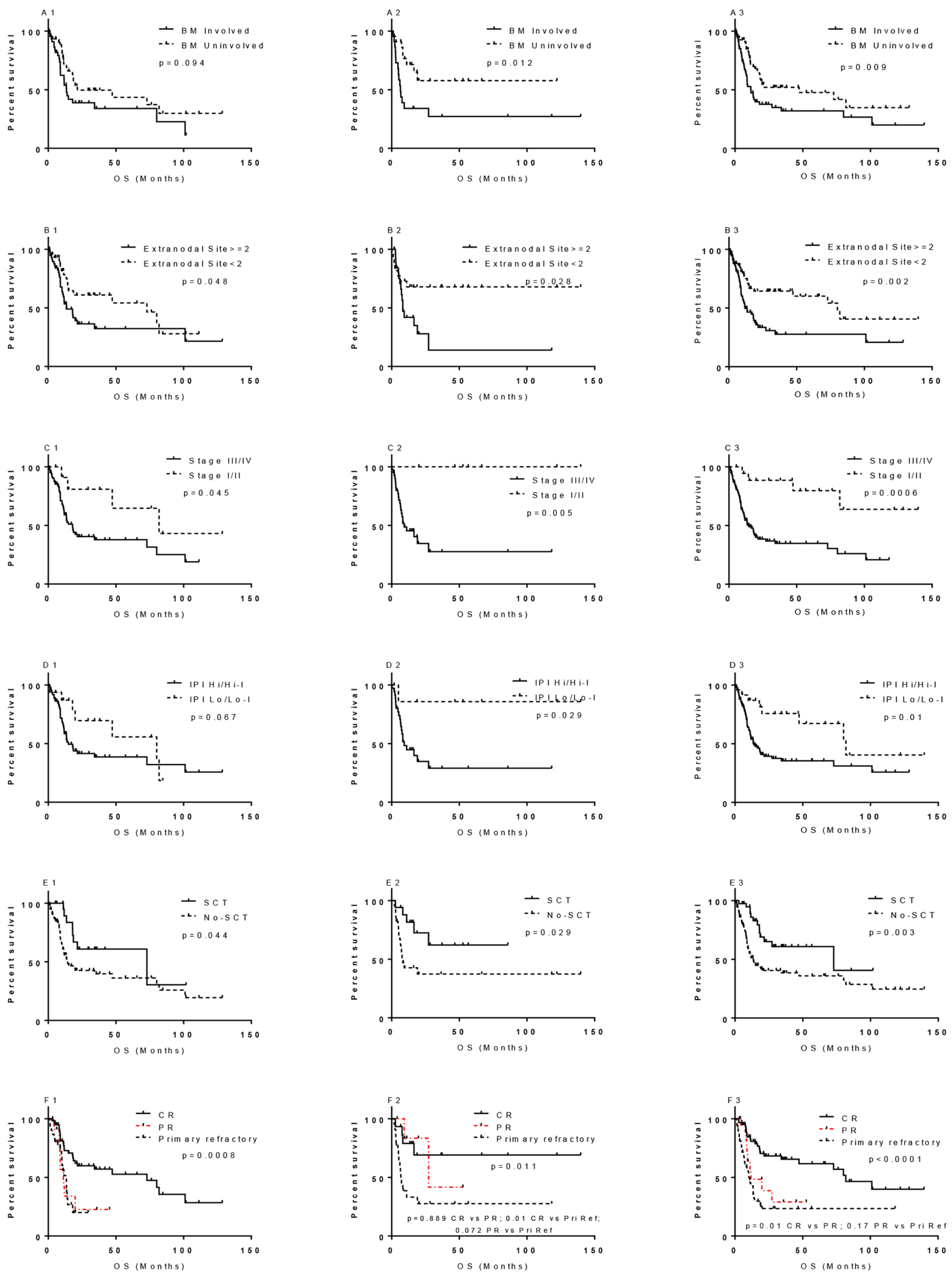

Figure 2: Prognostic significance of bone marrow (BM) involvement, extranodal involvement, stage, IPI, SCT, and CR in overall survival of $M Y C / B C L 2$ lymphoma. All label include "1" indicate patients with de novo DHL; those include " 2 " indicate DHL patients with history of follicular lymphoma; and those include "3" for all DHL. 
Table 3: Multivariate analysis of clinicopathologic features predictive of overall survival in all DHL patients

Features
\begin{tabular}{|l|c|c|c|}
\hline BM involvement & Hazard Ratio & 95\% Confidence of Interval & $P$ \\
\hline Extranodal sites $\geq \mathbf{2}$ & 0.92 & $0.48-1.80$ & 0.817 \\
\hline Stage III /IV vs I/II & 1.12 & $0.48-2.65$ & 0.793 \\
\hline IPI (H/H-I vs L/L-I) & $\mathbf{3 4 . 4 5}$ & $\mathbf{4 . 9 2 - 2 4 1 . 3 1}$ & $<\mathbf{0 . 0 0 1}$ \\
\hline Initial Chemotherapy & $\mathbf{3 . 0 0}$ & $\mathbf{1 . 1 4 - 7 . 7 7}$ & $\mathbf{0 . 0 2 6}$ \\
\hline R-EPOCH vs R-CHOP & & & 0.723 \\
\hline R-HCVAD vs R-CHOP & 1.17 & $0.49-2.84$ & 0.894 \\
\hline Stem cell transplant & 0.95 & $0.47-1.93$ & $<\mathbf{0 . 0 0 1}$ \\
\hline CR after initial chemotherapy & $\mathbf{0 . 2 2}$ & $\mathbf{0 . 1 0 - 0 . 4 6}$ & $<\mathbf{0 . 0 0 1}$ \\
\hline
\end{tabular}

Bold: prognostic factors with $P<0.05$.

transformation, but it is unclear if it conveys a poorer prognosis than de novo disease [27]. The results in this study show that clinicopathologic features are virtually the same for patients with de novo versus transformed $M Y C / B C L 2$ DHL and that OS was similar for both patient groups. These results suggest that a history of FL is not a worse prognostic factor in patients with $M Y C / B C L 2 \mathrm{DHL}$, perhaps because the prognosis in both groups is very poor.

The prognostic significance of several clinicopathologic factors in patients with $M Y C / B C L 2$ DHL is controversial in the literature. Pathologic classification of cases of $M Y C / B C L 2$ DHL is one of these issues. One previous study of 54 cases reported that patients with DHL in whom the tumor had DLBCL morphology had a significant better OS than patients with high-grade B cell lymphoma NOS/ BCLU morphology [11]. However, another study of 29 cases found that morphologic classification did not have prognostic implications [28]. The results in this large study suggest that morphologic classification of cases of MYC/BCL2 DHL does not correlate with prognosis, either in patients with de novo disease or in patients with a history of FL.

Another controversial prognostic factor is the translocation partner of $M Y C$. Johnson et al reported that cases of $M Y C / B C L 2$ DHL in which $M Y C$ is partnered with a non $I G$ locus had a better prognosis.[11] Two recent studies have shown that the adverse prognostic impact of $M Y C$ rearrangement correlates with $M Y C-I G$ translocation in de novo DLBCL patients treated with immunochemotherapy $[29,30]$. In contrast, the study by Aukema and colleagues showed that the $M Y C$ partner $(I G$ versus non- $I G)$ had no prognostic significance in $M Y C$ rearrangement positive B-cell lymphoma (excluding Burkitt lymphoma) [9]. One of the limitations of earlier studies is that the assessed patient cohorts were a mixed group that included $M Y C$ single hit lymphoma, all types of DHL and triple hit lymphomas, and patients did not receive immunochemotherapy in the study by Aukema et al.
In this study, there were 40 cases of $M Y C / B C L 2$ DHL in which the partner of $M Y C$ is known. These 40 cases are a pure group of $M Y C / B C L 2$ DHL, in other words no other DHL or triple hit lymphoma cases, and most patients received immunochemotherapy. Survival analysis showed there was no significant prognostic difference between patients with MYC/BCL2 DHL in which the MYC partner was $I G$ versus non- $I G$. Additional large and prospective studies focused on MYC/BCL2 DHL are needed.

In recent years, the use of immunohistochemical analysis has identified a subset of DLBCL cases that are double positive (DPL) or double-expressers of MYC and BCL2. MYC protein expression or MYC and BCL2 dual expression have been shown to be associated with a worse prognosis in patients with DLBCL treated with R-CHOP $[31,32]$. However, MYC/BCL2 DHL and MYC/BCL2 DPL are not concordant; DPL is much more common $(20-30 \%$ of DLBCL) than DHL ( $10 \%$ of DLBCL) and not all $M Y C / B C L 2$ DHL are DPL [31-33]. Furthermore, $M Y C$ translocation is a poor prognostic factor in DPL [33]. Does MYC or MYC and BCL2 dual expression have the same prognostic effect in $M Y C / B C L 2$ DHL as they do in DLBCL? The results in our current study show that both MYC expression alone and MYC/BCL2 double expression have no prognostic significance in patients with $M Y C / B C L 2$ DHL, suggesting that the impact of gene translocation trumps detected protein expression.

The clinicopathologic features in this cohort of patients with $M Y C / B C L 2$ DHL are similar to those reported in the literature. In this study, despite various immunochemotherapy regimens and SCT in a subset of patients, the median OS was 19 months and the 2 year survival rate was $47 \%$. Previous studies have shown conflicting results regarding different chemotherapy regimens and effect of SCT. Some studies showed a possible favorable outcome for patients who received R-EPOCH chemotherapy or SCT [34, 35]. In contrast, other studies demonstrated no prognostic difference for 
different chemotherapy regimens as well as SCT [11, 14]. Recently, Oki et al. [18] reported 129 patients with $M Y C$ abnormalities including $93 \mathrm{MYC} / \mathrm{BCL} 2 \mathrm{DHL}$. In that study, the CR rate was higher in patients who received frontline R-EPOCH (68\%) or R-Hyper-CVAD/M (68\%) than in patients who received R-CHOP $(40 \% ; P \approx 0.01$ for both comparisons). However, only patients receiving R-EPOCH demonstrated a longer EFS $(P=.004)$ and OS $(P=.057)$ than those who received R-CHOP. In patients who achieved a CR with induction therapy $(n=71)$, the 2-year OS rates were not statistically different between patients with $(n=23)$ or without $(n=48) \mathrm{SCT}$. In another large, retrospective study by Petrich et al. that included 311 patients with DHL from 23 academic centers [20], intensive induction regimens (R-EPOCH, R-HyperCVAD, and R-CODOX-M) improved PFS ( $p=0.001)$ but not OS $(p=0.564)$. Among patients who achieved CR after induction therapy, median OS was similar for those patients who did not undergo SCT (103 months) versus those who underwent consolidation SCT of any type (OS not reached; $P=0.14$ ). Both studies suggested that achieving $\mathrm{CR}$ with induction therapy, a measure of chemotherapy sensitivity, was a more important predictive factor of outcome than type of induction therapy or received SCT or not.
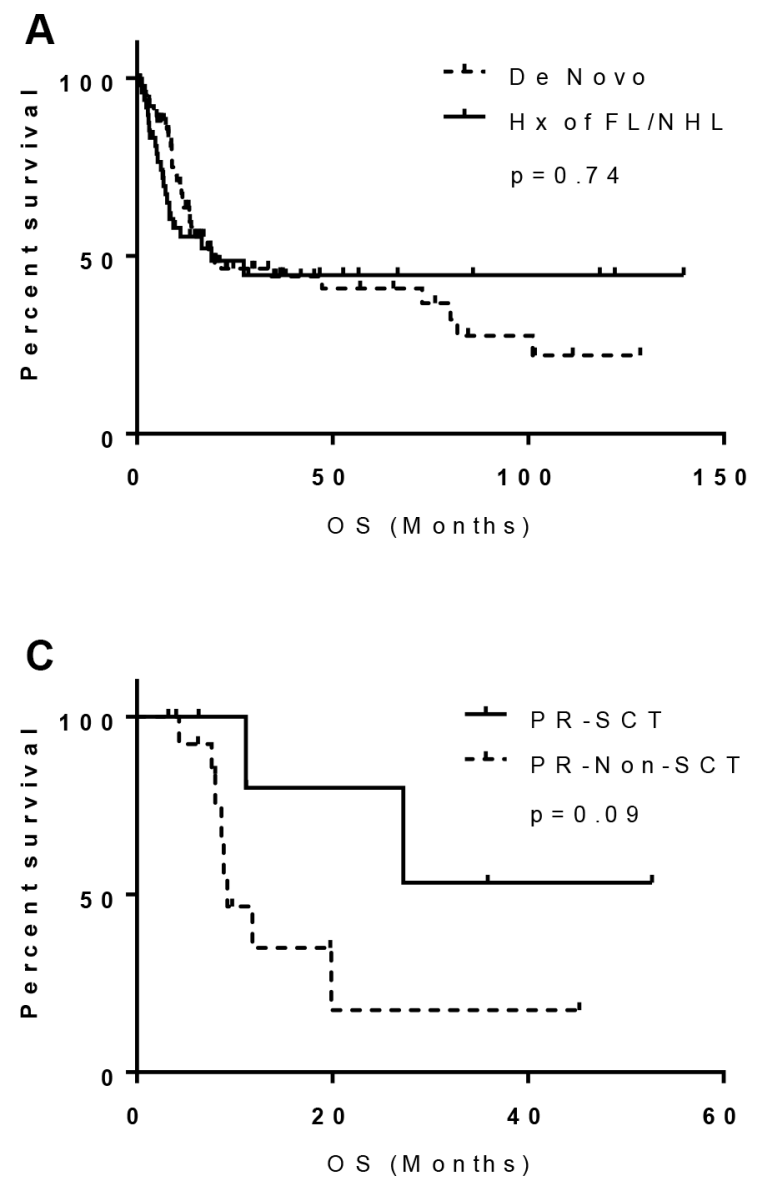

In this study, patients treated with R-EPOCH showed a trend towards better OS, but the difference between $\mathrm{R}-\mathrm{EPOCH}$ and R-CHOP was not statistically significant. This result is similar to the study by Petrich et al. discussed above, but is different from the results of the study by Oki et al. A possible explanation for the discrepancy is that the patient populations were different: our current study group only included the traditional translocation defined $M Y C /$ $B C L 2$ DHL. In contrast, the study from Oki et al. included traditional translocation defined $M Y C / B C L 2$ DHL, $M Y C /$ $B C L 6$ DHL, and MYC/BCL2/BCL6 triple hit lymphoma, as well as cases with extracopies of $M Y C, B C L 2$, or BCL6. In keeping with other studies, the results we present also show that achieving $\mathrm{CR}$ is an independent prognostic factor for OS regardless of type of frontline chemotherapy. Although SCT was an independent prognostic factor for OS in this patient cohort, further analysis showed that SCT did not play a role in prognosis if patients reached CR. However, patients who failed to achieve CR had a significant better OS when they received SCT compared to those without SCT $(p<0.05)$, an effect that has not been observed previously. Our results suggest that $M Y C / B C L 2$ DHL patients who fail to achieve CR might benefit from SCT. As this study is retrospective, we acknowledge that additional prospective studies are needed to definitively address this issue.
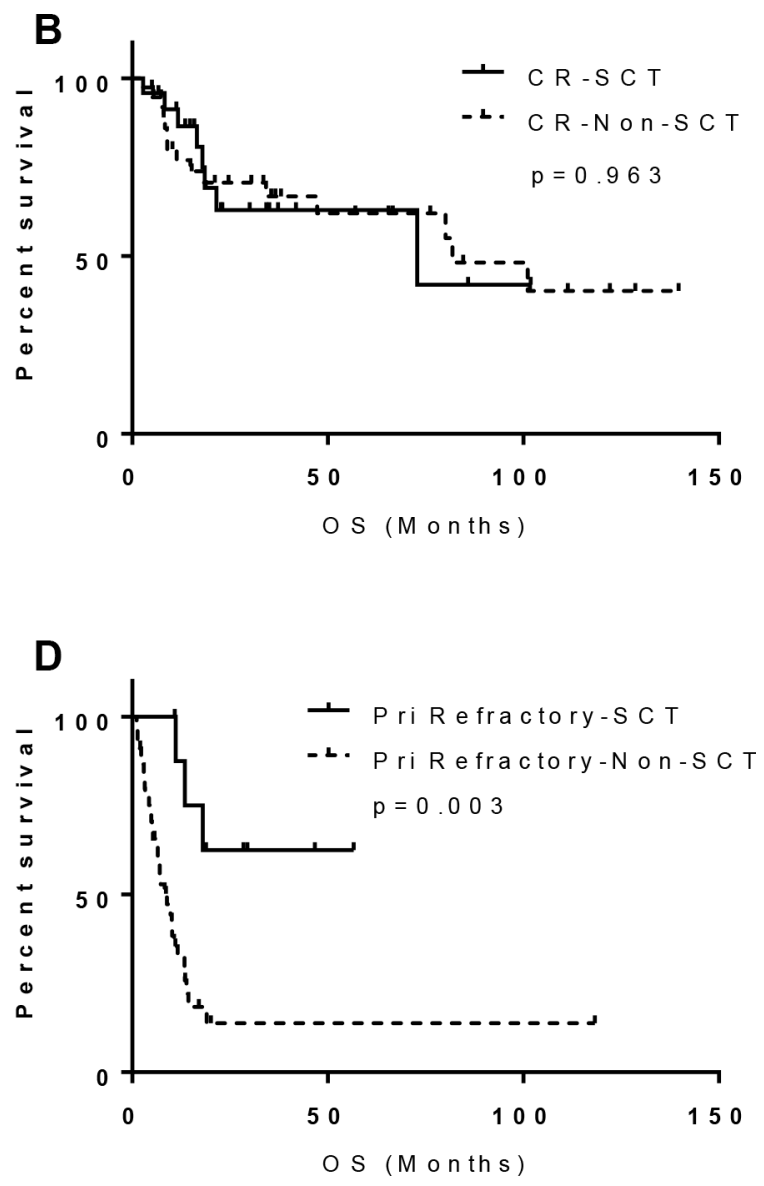

Figure 3: Prognostic significance of history of follicular lymphoma and SCT in MYC/BCL2 DHL: (A) History of FL; (B) patients achieved CR; (C) patients achieved PR; and (D) patients with primary refractory disease. 
In conclusion, we showed that achievement of $\mathrm{CR}$, use of SCT, stage, and IPI are independent prognostic factors in patients with $M Y C / B C L 2$ DHL and that patients who failed to achieve CR after induction chemotherapy may benefit from SCT. We also show that a history of FL, morphologic classification (DLBCL versus highgrade B-cell lymphoma NOS), MYC expression, BCL2 expression, MYC and BCL2 dual expression, MYC translocation partner gene, and induction chemotherapy regimens were not associated with prognosis. To our knowledge, this is the first study that has systemically compared the clinicopathologic features and prognostic factors in patients with de novo MYC/BCL2 DHL to patients who have a history of FL before developing $M Y C /$ $B C L 2$ DHL.

\section{MATERIALS AND METHODS}

\section{Case selection}

A total of 157 patients diagnosed with $M Y C /$ $B C L 2$ DHL were included in this study. This neoplasm is defined as a large B-cell lymphoma (either DLBCL or high-grade B-cell lymphoma NOS) with concurrent $M Y C$ and $B C L 2$ rearrangements. The designation highgrade B-cell lymphoma NOS has replaced the term BCLU in the upcoming new World Health Organization classification [6].

The cases in this study span the years of 2003 through 2015 with most cases accessioned in the recent five years. A small subset of cases has been reported previously [14]. Corresponding medical records were reviewed to obtain clinical information, including a history of lymphoma, number and sites of involvement, Ann Arbor stage, IPI score, treatment regimens, response to therapy, and overall survival. The study has been approved by our institutional review board.

\section{Immunophenotyping}

Imunohistochemical analysis was performed using formalin-fixed, paraffin-embedded tissue sections, either at the time of diagnosis or retrospectively for this study. The panel of monoclonal antibodies used was variable over time but included reagents specific for CD3 and CD20 (Ventana Medical Systems, Tucson, Arizona, USA); CD5, CD10, BCL2, BCL6, and MUM1/ IRF4 (Leica Microsystems, Buffalo Grove, IL, USA); MYC (Epitomics, Burlingame, CA, USA); and Ki-67 (MIB-1) (DAKO, Carpinteria, CA, USA). The cutoffs for positivity for CD10, BCL6, and MUM1 were 30\% as were used by Hans and colleagues [24]. The positive cutoffs for MYC and BCL2 were $\geq 40 \%$ and $\geq 50 \%$ of cells, respectively, as have been used earlier and by others $[32,33,36-39]$.
Flow cytometry immunophenotypic analysis was performed using standard multicolor analysis, four-color in cases accessioned earlier and mostly eight-color in recent years. Analysis was performed using FACScanto II or FACS-Calibur cytometer (Becton-Dickinson Biosciences, San Jose, CA, USA) as described previously. [14] Lymphocytes were gated for analysis using CD45 expression and side scatter. The panel was variable and included CD3, CD4, CD5, CD7, CD8, CD10, CD13, CD19, CD20, CD23, CD33, CD34, CD38 and kappa and lambda light chains. All antibodies were obtained from Becton-Dickinson Biosciences.

\section{Conventional cytogenetic studies and fluorescence in situ hybridization}

Conventional $\mathrm{G}$ band karyotype analysis was performed on $46 \mathrm{MYC/BCL2}$ DHL cases. The karyotypes were reported according to the 2013 International System for Human Cytogenetic Nomenclature [40].

Fluorescence in situ hybridization (FISH) analysis for MYC and BCL2 was performed in all cases using the LSI MYC dual-color break-apart and LSI IGH@BCL2 dual-color, dual fusion probes (Abbott Laboratories, Des Plaines, IL, USA). BCL6 gene status was tested by FISH using dual color break-apart probe. $M Y C / B C L 2$ DHL cases were identified if they had rearrangements of $M Y C$ and BCL2, but not BCL6 or 3q27 abnormalities by conventional karyotype. For bone marrow aspirate specimens, FISH was performed by using a freshly dropped slide from a harvested bone marrow or a G-banded slide for metaphase mapping according to the manufacturer's instructions. For formalin-fixed, paraffin-embedded tissue samples, FISH was performed on 4-micron thick tissue sections and fixed onto slides according to the manufacturer's protocol. The signals from 200 nuclei were analyzed.

\section{Statistical analysis}

Overall survival (OS) was calculated from date of diagnosis to the date of death or last follows up. Patient survival was analyzed using the Kaplan-Meier method and compared using the log rank test. Multivariate analysis was performed using Cox proportional hazards model. Statistical analysis was performed using SPSS 23 software. Fisher's exact test was used to compare the clinicopathologic features between patients with de novo versus patients with a history of low-grade B-cell lymphoma before $M Y C / B C L 2$ DHL. A $p$ value of less than 0.05 was considered significant.

\section{CONFLICTS OF INTEREST}

None. 


\section{REFERENCES}

1. Kluin PM HN, Stein H, Leoncini L, Raphael M, Campo E, Jaffe ES, Swerdlow SH, Campo E, Harris NL, Jaffe ES, Pileri SA, Stein H, Thiele J, et al. B-cell lymphoma, unclassifiable, with features intermediate between diffuse large B-cell lymphoma and Burkitt lymphoma. In: WHO Classification of Tumours of Haematopoietic and Lymphoid Tissues. (Lyon: IARC), 2008: 265-267.

2. Friedberg JW. Double-hit diffuse large B-cell lymphoma. Journal of clinical oncology. 2012; 30:3439-3443.

3. Aukema SM, Siebert R, Schuuring E, van Imhoff GW, Kluin-Nelemans HC, Boerma EJ, Kluin PM. Double-hit B-cell lymphomas. Blood. 2011; 117:2319-2331.

4. Li S, Lin P, Young KH, Kanagal-Shamanna R, Yin CC, Medeiros LJ. MYC/BCL2 double-hit high-grade B-Cell lymphoma. Advances in anatomic pathology. 2013; 20:315-326.

5. Landsburg DJ, Petrich AM, Abramson JS, Sohani AR, Press O, Cassaday R, Chavez JC, Song K, Zelenetz AD, Gandhi M, Shah N, Fenske TS, Jaso J, et al. Impact of oncogene rearrangement patterns on outcomes in patients with double-hit non-Hodgkin lymphoma. Cancer. 2016; 122:559-564.

6. Swerdlow SH, Campo E, Pileri SA, Harris NL, Stein H, Siebert R, Advani R, Ghielmini M, Salles GA, Zelenetz AD, Jaffe ES. The 2016 revision of the World Health Organization (WHO) classification of lymphoid neoplasms. Blood. 2016.

7. Slack GW, Gascoyne RD. MYC and aggressive B-cell lymphomas. Advances in anatomic pathology. 2011; 18:219-228.

8. Smith SM, Anastasi J, Cohen KS, Godley LA. The impact of MYC expression in lymphoma biology: beyond Burkitt lymphoma. Blood Cells, molecules, and diseases. 2010; 45:317-323.

9. Aukema SM, Kreuz M, Kohler CW, Rosolowski M, Hasenclever D, Hummel M, Kuppers R, Lenze D, Ott G, Pott C, Richter J, Rosenwald A, Szczepanowski M, et al. Biological characterization of adult MYC-translocationpositive mature B-cell lymphomas other than molecular Burkitt lymphoma. Haematologica. 2014; 99:726-735.

10. Bertrand P, Bastard C, Maingonnat C, Jardin F, Maisonneuve C, Courel MN, Ruminy P, Picquenot JM, Tilly H. Mapping of MYC breakpoints in 8q24 rearrangements involving nonimmunoglobulin partners in B-cell lymphomas. Leukemia. 2007; 21:515-523.

11. Johnson NA, Savage KJ, Ludkovski O, Ben-Neriah S, Woods R, Steidl C, Dyer MJ, Siebert R, Kuruvilla J, Klasa R, Connors JM, Gascoyne RD, Horsman DE. Lymphomas with concurrent BCL2 and MYC translocations: the critical factors associated with survival. Blood. 2009; 114:2273-2279.

12. Kanungo A, Medeiros LJ, Abruzzo LV, Lin P. Lymphoid neoplasms associated with concurrent $\mathrm{t}(14 ; 18)$ and 8q24/ c-MYC translocation generally have a poor prognosis. Modern pathology. 2006; 19:25-33.
13. Le Gouill S, Talmant P, Touzeau C, Moreau A, Garand R, Juge-Morineau N, Gaillard F, Gastinne T, Milpied N, Moreau P, Harousseau JL, Avet-Loiseau H. The clinical presentation and prognosis of diffuse large B-cell lymphoma with $\mathrm{t}(14 ; 18)$ and 8q24/c-MYC rearrangement. Haematologica. 2007; 92:1335-1342.

14. Li S, Lin P, Fayad LE, Lennon PA, Miranda RN, Yin CC, Lin E, Medeiros LJ. B-cell lymphomas with MYC/8q24 rearrangements and IGH@BCL2/t(14;18)(q32;q21): an aggressive disease with heterogeneous histology, germinal center B-cell immunophenotype and poor outcome. Modern pathology. 2012; 25:145-156.

15. Lin $\mathrm{P}$, Medeiros LJ. High-grade B-cell lymphoma/leukemia associated with $\mathrm{t}(14 ; 18)$ and $8 \mathrm{q} 24 / \mathrm{MYC}$ rearrangement: a neoplasm of germinal center immunophenotype with poor prognosis. Haematologica. 2007; 92:1297-1301.

16. Macpherson N, Lesack D, Klasa R, Horsman D, Connors JM, Barnett M, Gascoyne RD. Small noncleaved, non-Burkitt's (Burkit-Like) lymphoma: cytogenetics predict outcome and reflect clinical presentation. Journal of clinical oncology. 1999; 17:1558-1567.

17. Niitsu N, Okamoto M, Miura I, Hirano M. Clinical features and prognosis of de novo diffuse large B-cell lymphoma with $\mathrm{t}(14 ; 18)$ and $8 \mathrm{q} 24 / \mathrm{c}-\mathrm{MYC}$ translocations. Leukemia. 2009; 23:777-783.

18. Oki Y, Noorani M, Lin P, Davis RE, Neelapu SS, Ma L, Ahmed M, Rodriguez MA, Hagemeister FB, Fowler N, Wang M, Fanale MA, Nastoupil L, et al. Double hit lymphoma: the MD Anderson Cancer Center clinical experience. British journal of haematology. 2014; 166:891-901.

19. Pedersen MO, Gang AO, Poulsen TS, Knudsen H, Lauritzen AF, Nielsen SL, Gang UO, Norgaard P. Double-hit BCL2/MYC translocations in a consecutive cohort of patients with large B-cell lymphoma - a single centre's experience. European journal of haematology. 2012; 89:63-71.

20. Petrich AM, Gandhi M, Jovanovic B, Castillo JJ, Rajguru S, Yang DT, Shah KA, Whyman JD, Lansigan F, HernandezIlizaliturri FJ, Lee LX, Barta SK, Melinamani S, et al. Impact of induction regimen and stem cell transplantation on outcomes in double-hit lymphoma: a multicenter retrospective analysis. Blood. 2014; 124:2354-2361.

21. Tomita N, Tokunaka M, Nakamura N, Takeuchi K, Koike J, Motomura S, Miyamoto K, Kikuchi A, Hyo R, Yakushijin Y, Masaki Y, Fujii S, Hayashi T, et al. Clinicopathological features of lymphoma/leukemia patients carrying both BCL2 and MYC translocations. Haematologica. 2009; 94:935-943.

22. Tsai JP, Iams WT, Greer JP, Morgan DS, Li S, Reddy NM. Alternative intensive induction chemotherapeutic regimens in MYC expressing diffuse large B-cell lymphoma. Leukemia \& lymphoma. 2015; 56:797-800.

23. Snuderl M, Kolman OK, Chen YB, Hsu JJ, Ackerman AM, Dal Cin P, Ferry JA, Harris NL, Hasserjian RP, Zukerberg LR, Abramson JS, Hochberg EP, Lee H, et al. B-cell lymphomas with concurrent IGH-BCL2 and MYC rearrangements are aggressive neoplasms with clinical and pathologic features 
distinct from Burkitt lymphoma and diffuse large B-cell lymphoma. The American journal of surgical pathology. 2010; 34:327-340.

24. Hans CP, Weisenburger DD, Greiner TC, Gascoyne RD, Delabie J, Ott G, Muller-Hermelink HK, Campo E, Braziel RM, Jaffe ES, Pan Z, Farinha P, Smith LM, et al. Confirmation of the molecular classification of diffuse large B-cell lymphoma by immunohistochemistry using a tissue microarray. Blood. 2004; 103:275-282.

25. Casulo C, Burack WR, Friedberg JW. Transformed follicular non-Hodgkin lymphoma. Blood. 2015; 125:40-47.

26. Montoto S, Fitzgibbon J. Transformation of indolent B-cell lymphomas. Journal of clinical oncology. 2011; 29:1827-1834.

27. Swerdlow SH. Diagnosis of 'double hit' diffuse large B-cell lymphoma and B-cell lymphoma, unclassifiable, with features intermediate between DLBCL, Burkitt lymphoma: when and how, FISH versus IHC. Hematology/the Education Program of the American Society of Hematology American Society of Hematology Education Program. 2014; 2014:90-99.

28. Cohen JB, Geyer SM, Lozanski G, Zhao W, Heerema NA, Hall NC, Nagar VA, Hemminger JA, Jones JA, Porcu P, Christian BA, Baiocchi RA, Maddocks KJ, et al. Complete response to induction therapy in patients with Myc-positive and double-hit non-Hodgkin lymphoma is associated with prolonged progression-free survival. Cancer. 2014; 120:1677-1685.

29. Copie-Bergman C, Cuilliere-Dartigues P, Baia M, Briere J, Delarue R, Canioni D, Salles G, Parrens M, Belhadj K, Fabiani B, Recher C, Petrella T, Ketterer N, et al. MYCIG rearrangements are negative predictors of survival in DLBCL patients treated with immunochemotherapy: a GELA/LYSA study. Blood. 2015; 126:2466-2474.

30. Pedersen MO, Gang AO, Poulsen TS, Knudsen H, Lauritzen AF, Nielsen SL, Klausen TW, Norgaard P. MYC translocation partner gene determines survival of patients with large B-cell lymphoma with MYC- or double-hit MYC/BCL2 translocations. European journal of haematology. 2014; 92:42-48.

31. Green TM, Young KH, Visco C, Xu-Monette ZY, Orazi A, Go RS, Nielsen O, Gadeberg OV, MouritsAndersen T, Frederiksen M, Pedersen LM, Moller MB. Immunohistochemical double-hit score is a strong predictor of outcome in patients with diffuse large B-cell lymphoma treated with rituximab plus cyclophosphamide, Doxorubicin, vincristine, and prednisone. Journal of clinical oncology. 2012; 30:3460-3467.

32. Johnson NA, Slack GW, Savage KJ, Connors JM, BenNeriah S, Rogic S, Scott DW, Tan KL, Steidl C, Sehn LH, Chan WC, Iqbal J, Meyer PN, et al. Concurrent Expression of MYC, BCL2 in Diffuse Large B-Cell Lymphoma Treated With Rituximab Plus Cyclophosphamide, Doxorubicin, Vincristine, and Prednisone. Journal of clinical oncology. 2012; 30:3452-3459.
33. Wang $\mathrm{XJ}$, Medeiros $\mathrm{LJ}$, Lin $\mathrm{P}$, Yin $\mathrm{CC}, \mathrm{Hu} \mathrm{S}$, Thompson MA, Li S. MYC Cytogenetic Status Correlates With Expression and Has Prognostic Significance in Patients With MYC/BCL2 Protein Double-positive Diffuse Large B-cell Lymphoma. The American journal of surgical pathology. 2015; 39:1250-1258.

34. Abramson JS BJ, Feng Y, Takvorian T, Neuberg DS, Hochberg EP, Sohani AR. Double hit lymphomas: evaluation of prognostic factors and impact of therapy. 2012 American Society of Hematology Annual Meeting. (December 8-11, 2012; Atlanta, GA. Abstract 1619.

35. Howlett C GA, Zielonka T, Pecora AL, Feldman T, Rowley SD, Donato ML, et al. Dose intensive induction followed by allogeneic stem cell transplantation more than doubles progression-free and overall survival in "doublehit' lymphoma. Presented at: the 2013 American Society of Hematology Annual Meeting; December 7-10, 2013; New Orleans, LA. Blood. 2013. Abstract 2141. Blood. 2013; 122:2141.

36. Li S, Desai P, Lin P, Yin CC, Tang G, Wang XJ, Konoplev SN, Khoury JD, Bueso-Ramos CE, Medeiros LJ. MYC/ BCL6 double-hit lymphoma (DHL): a tumour associated with an aggressive clinical course and poor prognosis. Histopathology. 2015 Oct 1. doi: 10.1111/his.12884.

37. Li S, Seegmiller AC, Lin P, Wang XJ, Miranda RN, Bhagavathi S, Medeiros LJ. B-cell lymphomas with concurrent MYC, BCL2 abnormalities other than translocations behave similarly to MYC/BCL2 double-hit lymphomas. Modern pathology. 2015; 28:208-217.

38. Li S, Weiss VL, Wang XJ, Desai PA, Hu S, Yin CC, Tang G, Reddy NM, Medeiros LJ, Lin P. High-grade B-cell Lymphoma With MYC Rearrangement and Without BCL2 and BCL6 Rearrangements Is Associated With High P53 Expression and a Poor Prognosis. The American journal of surgical pathology. 2016; 40:253-261.

39. Visco C, Tzankov A, Xu-Monette ZY, Miranda RN, Tai YC, Li Y, Liu WM, d'Amore ES, Montes-Moreno S, Dybkaer K, Chiu A, Orazi A, Zu Y, et al. Patients with diffuse large B-cell lymphoma of germinal center origin with BCL2 translocations have poor outcome, irrespective of MYC status: a report from an International DLBCL rituximabCHOP Consortium Program Study. Haematologica. 2013; 98:255-263.

40. Shaffer LG M-JJ, Schmid M. (2012). An International System for Human Cytogenetic Nomenclature (2013), Karger: Basel, Switzerland). 